\title{
Análise de exames de imunofluorescência direta para o diagnóstico de tracoma*
}

\section{Analysis of direct immunofluorescence exams for trachoma diagnosis}

\author{
Norma H. Medina, Rosana M. Gentil, Márcia Caraça, César K. Suzuki, Heloísa H. B. \\ Melles \\ Serviço de Oftalmologia Sanitária do Centro de Apoio e Desenvolvimento de Assistência Integral à \\ Saúde da Secretaria de Estado da Saúde. São Paulo, SP - Brasil (N. H. M.; R. M. G.; C. K. S.); Centro \\ de Vigilância Epidemiológica "Alexandre Vranjac" da Secretaria de Estado da Saúde. São Paulo, SP - \\ Brasil (M. C.); Instituto Adolfo Lutz - Central da Secretaria de Estado da Saúde. São Paulo, SP - Brasil \\ (H. H. B. M.)
}

\begin{abstract}
Resumo
Para confirmação de foco de tracoma em locais onde não existiam casos anteriormente relatados, a Secretaria de Estado da Saúde preconiza a realização de exames laboratoriais principalmente pelo fato da doença ter sido considerada erradicada no Estado de São Paulo, Brasil, na década de 70. Foram colhidas, durante investigações epidemiológicas, lâminas de raspado conjuntival de indivíduos com diagnóstico clínico de tracoma inflamatório (TF/TI). Analisaramse os resultados dos exames laboratoriais por imunofluorescência direta (IFD), quanto à freqüência de exames adequados para análise e sua positividade segundo a quantidade de corpúsculos elementares (EBs) encontrados (sensibilidade do teste). Foram estudadas 385 lâminas, sendo que 241 (62,6\%) foram consideradas adequadas para análise. Considerando-se o critério de positividade de 5 ou + EBs, a sensibilidade do teste foi de 19,9\%. O teste de IFD apesar de ser o melhor teste laboratorial para ser utilizado em trabalhos de campo, não apresenta sensibilidade suficiente para confirmar todos os casos clínicos diagnosticados de tracoma, mas pode confirmar a circulação do agente etiológico em uma comunidade. Portanto, em zonas endêmicas o diagnóstico clínico de tracoma continua sendo o critério para confirmação de casos.
\end{abstract}

Tracoma, diagnóstico. Imunofluorescência, utilização.

\begin{abstract}
For the confirmation of trachoma foci in places where no previous cases had been reported, the State Health Secretariat of S. Paulo makes provision for the realization of laboratory exams, particularly because the disease was considered to have been eradicated from the State in the seventies. During the epidemiological investigations, conjuntival scrapings were collected from the subjects with inflamatory trachoma (TF/TI), clinically diagnosed. The results
\end{abstract}

\footnotetext{
*Apresentado no X Congresso Brasileiro de Prevenção da Cegueira, Manaus/AM, 1992 e no II Congresso Brasileiro de Epidemiologia, Belo Horizonte/MG, 1992.

Correspondência para/Correspondence to: Norma H. Medina - Centro de Vigilância Epidemiológica da Secretaria de Estado da Saúde. Av. São Luiz, $996^{\circ}$ andar - Centro - 01046-001 São Paulo,SP - Brasil. Fax: (011) 258.6416

Edição subvencionada pela FAPESP. Processo 95/2290 - 6.

Recebido em 14.2.1995. Aprovado em 21.11.1995.
} 
of the immunofluorescence (DFA) exams were analysed in the light of the frequency of the appropriate exams and their positive results, by the quantity of elementary bodies (EB) found. A total of 385 slides were studied, the criteria for positivity being 5 or more EBs. The test's sensitivity was $19.9 \%$. The DFA test is considered to be the best laboratorial exam to be used in field work, though it does not show a sufficient sensitivity to confirm all clinically diagnosed cases of trachoma; it can only confirm the circulation of the aetiological agent within a community. In endemic areas the clinical diagnosis continues to be the criterion for case confirmation.

Trachoma, diagnosis. Fluorescent antibody technique, utilization.

\section{INTRODUÇÃO}

O tracoma é uma infecção ocular causada pela Chlamydia trachomatis que produz alterações oculares clinicamente características. O diagnóstico clínico em áreas endêmicas é simples e bem definido.

"Nos programas de controle do tracoma os exames laboratoriais não são indispensáveis. Entretanto, podem ser utilizados por diversas razões: para apoiar o diagnóstico clínico da doença em casos individuais; para medir a prevalência da infecção em uma comunidade onde o tracoma é endêmico (isto é, para calcular a intensidade da infecção); para avaliar o efeito do tratamento em indivíduos ou comunidades; para calcular a exposição total de uma população à infecção por clamídia; para avaliar mudanças no sorotipo dentro de uma população determinada que poderiam indicar a influência de um agente estranho à comunidade ou a possível transmissão de um reservatório genital" (Dawson e col. ${ }^{2}, 1981$ ).

Os exames laboratoriais mais utilizados para a demonstração do agente são a coloração de Giemsa, a cultura e a reação de imunofluorescência direta (IFD).

A coloração de Giemsa é uma técnica bem estabelecida, que apesar de sua alta especificidade, tem sensibilidade baixa e requer um microscopista altamente experiente, além de exigir muito tempo para a leitura de cada lâmina ${ }^{9,21}$. Esse longo tempo para um único exame inviabiliza seu emprego em trabalhos de campo, onde geralmente existe número elevado de $\operatorname{casos}^{20}$.

A cultura de Chlamydia trachomatis é o método padrão para o diagnóstico laboratorial, com alta sensibilidade, porém exige condições adequadas de realização, de estocagem de material, além de equipamentos sofisticados de alto custo que inviabilizam seu emprego no trabalho de campo ${ }^{3,9}$.

A imunofluorescência direta é realizada com a utilização de anticorpos monoclonais marcados, que se dirigem contra uma proteína comum aos 15 sorotipos da Chlamydia trachomatis, identificando os corpúsculos elementares extracelulares (EB) ao microscópio de fluorescência ${ }^{16}$. Em nosso meio a imunofluorescência direta é o método de escolha para o diagnóstico laboratorial ${ }^{8,14,15}$ por ser uma técnica suficientemente simples e rápida, não exigindo meios sofisticados de refrigeração para o transporte e estocagem, além de possuir requisitos suficientes quanto à sensibilidade e especificidade. Estudos indicam ser uma técnica que apresenta melhores resultados em termos de sensibilidade e especificidade que as demais técnicas disponíveis para o diagnóstico laboratorial de Chlamydia trachomatis $^{10,11,17,18,20 .}$

Para análise dos resultados da imunofluorescência direta existem critérios importantes a serem considerados em relação à qualidade do material colhido e ao número de corpúsculos elementares por lâmina. Uma lâmina é considerada adequada para análise, quando a quantidade de células epiteliais do raspado conjuntival for de pelo menos 100 células epiteliais ${ }^{20}$, sendo que este critério modificou recentemente o anterior, que era de 200 ou mais células ${ }^{19}$.

Não há concordância entre diversos autores quanto ao critério de positividade do exame. Alguns consideram o exame positivo com presença de pelo menos um EB ${ }^{7}$,outros com cinco ${ }^{8,10,19,20,21}$ e com dez $^{3,12,14,20 .}$

A Secretaria de Estado de Saúde de São Paulo (SES/SP) preconiza a realização de exames laboratoriais para confirmação de área com foco de tracoma, em locais onde não existiam casos previamente $^{15}$, pelo fato da doença ter sido considerada erradicada do Estado no final da década de $70^{5}$.

$\mathrm{O}$ presente trabalho visa a avaliar os resultados dos exames laboratoriais por imunofluorescência direta (IFD) realizados pela SES/SP, de casos clinicamente diagnosticados como tracoma inflamatório (TF/TI), quanto à frequiência de exames adequados para análise e a positividade segundo a quantidade de EBs encontrados (sensibilidade do teste). 


\section{MATERIAL E MÉTODO}

Foi colhido material de raspado da conjuntiva tarsal superior de indivíduos com diagnóstico clínico de tracoma inflamatório (TF/TI), durante as investigações realizadas pela vigilância epidemiológica da SES/SP, no período de janeiro de 1990 a dezembro de 1991.

Os examinadores receberam instruções teórico-práticas para reconhecer e classificar clinicamente os casos de tracoma segundo o critério preconizado pela Organização Mundial de Saúde ${ }^{21}$. Todos examinadores foram padronizados com nível de concordância de $80 \%$ dos diagnósticos com o monitor e também foram treinados para realizar coleta para o exame laboratorial.

Realizou-se coleta de raspado conjuntival da pálpebra superior evertida, sendo o swab esfregado por 10 vezes. O material obtido foi depositado no círculo da lâmina própria, deixou-se secar e fixou-se com metanol. As lâminas foram transportadas em caixas de isopor com gelo reciclável e ficaram estocados a $-20^{\circ} \mathrm{C}$ até o processamento e a leitura.

O material foi examinado no Instituto Adolfo Lutz Central por técnicos com experiência na execução da leitura pela reação de imunofluorescência direta.

Os esfregaços foram corados utilizando-se $25 \mu \mathrm{l}$ de anticorpos monoclonais conjugados à fluoresceína, dirigidos contra a principal proteína da membrana externa (MOMP), presente nos corpúsculos elementares (EBs) dos 15 sorotipos da Chlamydia trachomatis ${ }^{16}$.

Após 30 min de incubação em câmara úmida, à temperatura ambiente, as lâminas foram lavadas com água destilada e secas ao ar.

As lâminas foram examinadas em microscópio fluorescente com epi-iluminação, inicialmente com aumento de 400 vezes, visando ao rastreamento dos EBs, que se apresentavam como corpúsculos verdes fluorescentes característicos, os quais foram confirmados em aumento de mil vezes.

Os esfregaços foram analisados quanto ao número de células epiteliais, com o objetivo de avaliar sua qualidade, sendo agrupados em:

- menos de 100 células epiteliais;

- 100 ou mais células epiteliais;

- 200 ou mais células epiteliais.

Para avaliação dos resultados, utilizou-se a sensibilidade do teste que é a relação entre o número de resultados positivos e o número total de lâminas examinadas e testes estatísticos de significância.

\section{RESULTADOS}

Foram avaliadas 385 lâminas colhidas em diversos municípios do Estado de São Paulo. Do total de lâminas analisadas, 54 (14,0\%) apresentaram 200 células ou mais; 187 (48,6\%) apresentaram de 100 a 199 células e $144(37,4 \%)$ apresentaram menos que 100 células.

Segundo a Tabela 1, das 214 lâminas que não apresentam EBs, 106 (49,5\%) continham menos que 100 células epiteliais; das 82 lâminas que apresentaram 1 a 2 EBs, $56(68,3 \%)$ continham 100 ou mais células; das 35 lâminas que apresentaram 3 a 4 EBs, 29 (82,9\%) continham 100 ou mais células; das 37 lâminas apresentando 5 a 9 EBs, 31 (83,8\%) continham 100 ou mais células, e das 17 lâminas apresentando 10 ou mais EBs, 17 (100\%) continham 100 ou mais células.

O comportamento do IFD utilizando-se diferentes critérios de positividade do teste e quantidade de células epiteliais existentes no esfregaço encontrase na Figura. A maior sensibilidade encontrada para o teste de IFD foi de $55,6 \%$ nas lâminas contendo 200 células ou mais, utilizando-se o critério de 1 ou mais EBs como positivo. A sensibilidade do IFD foi diminuindo conforme a mudança do critério de positividade para 3 EBs $(35,2 \%), 5$ EBs $(27,8 \%)$ e 10 EBs $(12,9 \%)$

Os valores da sensibilidade encontrados para as lâminas com 100 ou mais células foram menores que as das lâminas com 200 ou mais células, independente do critério de positividade adotado, porém estas diferenças não foram estatisticamente significantes $(\mathrm{p}>0,005)$.

As lâminas com menos de 100 células apresentaram sensibilidades que variaram de $26,4 \%$, quando o critério de positividade foi igual a 1 ou mais EBs, a zero, quando o critério de positividade foi igual 10 ou mais EBs. A sensibilidade do teste nessas lâminas foi consideravelmente menor do que a das lâminas com 100 ou mais células e 200 ou mais células, utilizando-se qualquer um dos critérios de positividade.

Tabela 1 - Distribuição das lâminas de Imunofluorescência direta para Chlamydia trachomatis, segundo quantidade de células epiteliais por número de corpúsculos elementares (EBs), Estado de São Paulo, 1991.

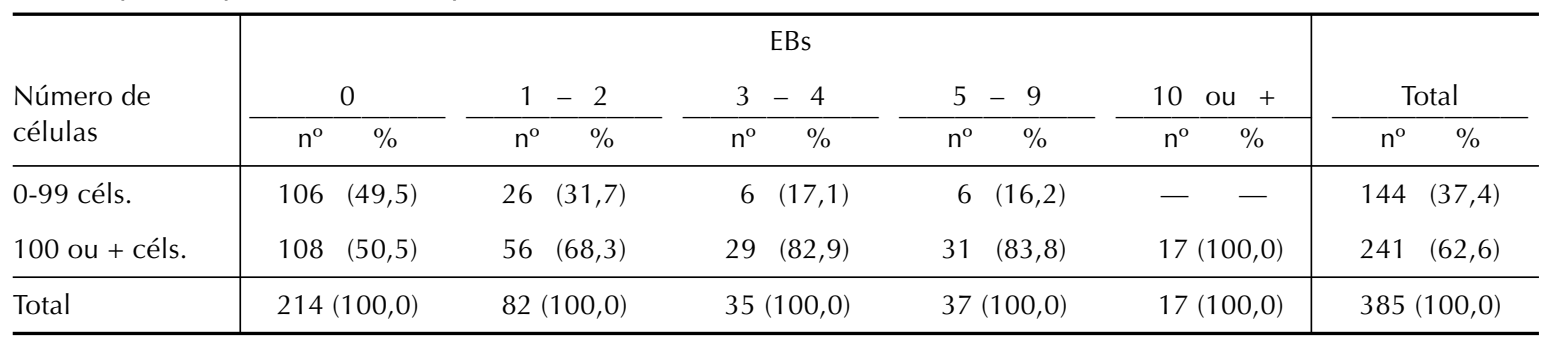




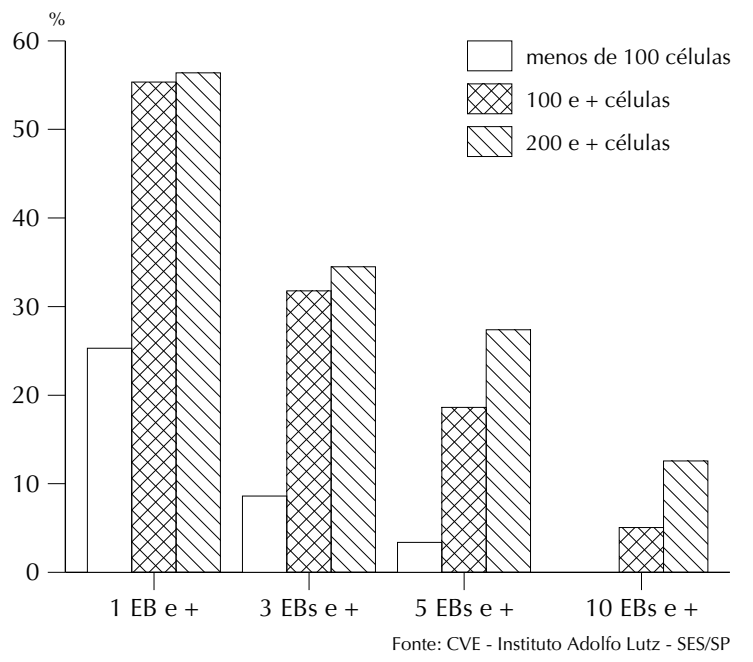

Figura - Lâminas de imunofluorescência direta (IFD) para C. trachomatis, segundo quantidade de corpúsculos elementares (EBs) e de células. Estado de São Paulo - 1991

Comparando-se estas lâminas com os outros dois grupos de lâminas, as diferenças foram estatisticamente significantes para todos os critérios de positividade $(\mathrm{p}<0,005)$ (Fig.).

A sensibilidade do teste de IFD nas lâminas apresentando 100 ou mais células foi de 19,9\%, considerando o critério de positividade de 5 ou mais EBs e de 7,1\%, quando o critério foi de 10 ou mais EBs; nas lâminas contendo 200 células ou mais a sensibilidade foi de $27,8 \%$, com o critério de positividade de 5 ou mais EBs, e de $12,9 \%$, com o critério de 10 ou mais EBs (Tabela 2).

A diferença de sensibilidade entre as lâminas de 100 células ou mais e de 200 células ou mais, considerando-se os dois critérios de positividade, não foi estatisticamente significante ( 5 EBs: $X^{2}=1,62$ e $p=$ 0,203; 10 EBs: $X^{2}=2,06$ e $\left.p=0,151\right)$.

\section{DISCUSSÃO}

No presente estudo foram analisadas 385 lâminas de raspado conjuntival pela técnica de IFD para Chlamydia trachomatis; a maioria das lâminas ana- lisadas $(62,6 \%)$ apresentaram 100 células epiteliais ou mais. Verificou-se que a percentagem de lâminas com 100 ou mais células aumentou proporcionalmente com o número de EBs encontrado: 1 e 2 EBs $(68,3 \%) ; 3$ e 4 EBs $(82,9 \%) ; 5$ a $9(83,8 \%)$ e 10 ou mais EBs (100\%) (Tabela 1).

A sensibilidade do teste de IFD nas lâminas contendo menos que 100 células apresentou-se mais baixa que a das lâminas contendo 100 ou mais células e 200 ou mais células, considerando-se qualquer um dos critérios de positividade. A diferença foi estatisticamente significante.

A diferença da sensibilidade entre as lâminas contendo 100 ou mais células e 200 ou mais células, considerando-se todos os critérios de positividade adotados não foi estatisticamente significante, apesar da sensibilidade das lâminas com 200 ou mais células ter sido maior. Dessa forma o critério para se considerar uma lâmina adequada para análise deve ser de 100 células ou mais devido aos resultados estatísticos encontrados, o que está de acordo com os resultados de Taylor ${ }^{20}$, 1991. A qualidade das lâminas de IFD é mencionada em trabalhos científicos ${ }^{8}$, 19, 20 e lâminas inadequadas para análise geralmente são retiradas do estudo.

Apesar deste fato, nos trabalhos de campo onde o objetivo é detectar a circulação do agente etiológico, configurando foco de doença, analisamse também as lâminas de qualidade inadequada, isto é, com número menor que 100 células epiteliais, pois ainda que não preencham as exigências de qualidade, preenchem os critérios de positividade.

Segundo a Tabela 2, a sensibilidade do IFD variou de $19,9 \%$ a $27,8 \%$, considerando-se o critério de positividade de 5 ou mais EBs, para as lâminas com 100 ou mais células ou 200 ou mais células, respectivamente. Considerando o critério de positividade de 10 ou mais EBs, a sensibilidade do teste variou de $7,1 \%$ a $12,9 \%$. Essas diferenças não foram significantes estatisticamente $(\mathrm{p}>0,005)$.

Estudos sobre a sensibilidade do teste utilizando a clínica como padrão e o critério de positividade de 5 ou mais EBs, mostraram resultados que variaram de $11 \%^{10}, 13,3 \%{ }^{13}, 19,4 \%{ }^{8}, 38 \%^{20}$ a $54,7 \%{ }^{19}$. Outros estudos utilizando o critério de positividade de 10 ou mais EBs mostraram resultados que variaram de

Tabela 2 - Sensibilidade do teste de imunofluorecência direta (IFD) para Chlamydia trachomatis, segundo quantidade de células no esfregaço conjuntival e número de corpúsculos elementares presentes, Estado de São Paulo, 1991.

\begin{tabular}{c|c|c|c}
\hline Número de células & 5 EBs ou + & 10 EBs ou + & Número total lâminas \\
\hline 100 ou + células & $48 / 241(19,9 \%)$ & $17 / 241(7,1 \%)$ & 241 \\
200 ou + células & $15 / 54(27,8 \%)$ & $7 / 54(12,9 \%)$ & 54 \\
\hline
\end{tabular}


zero, $13,8 \%^{20}, 9,9 \%^{3}, 66,7 \%^{14}$ a $69,3 \%^{12}$. A sensibilidades do teste de IFD no presente trabalho encontrase próxima à maioria dos estudos.

Um dos fatores que poderia influenciar na sensibilidade do teste seria a existência de uma correlação entre a infecção clamidiana e a intensidade do quadro clínico. Quanto mais grave o tracoma, maior a freqüência de detecção de inclusões clamidianas nos exames laboratoriais ${ }^{1,18}$.

Em trabalho realizado na Tunísia foram detectadas inclusões clamidianas em raspados conjuntivais em $49 \%$ dos casos severos, $23 \%$ dos casos moderados e $5 \%$ dos casos leves ${ }^{1}$.

A Clamídia não pode ser detectada por cultura ou citologia em macacos recebendo inoculações periódicas do agente etiológico após cerca de 10 semanas, independente da presença de reinoculação periódica contínua ${ }^{18}$.

Em humanos, a Clamídia também não foi detectada em muitos indivíduos com tracoma ativo, incluindo alguns deles com a doença mais severa ${ }^{1}$.

As lâminas foram colhidas em trabalhos sistemáticos da vigilância epidemiológica em que os resultados poderiam ser influenciados por dificuldades operacionais em nível de campo, tais como: muitos profissionais coletando material, problemas no transporte e outras condições adversas do campo; mesmo assim os resultados da sensibilidade encontram-se próximos dos trabalhos epidemiológicos que tentaram controlar essas variáveis adversas.

É consenso entre os epidemiologistas que "na prática muitas características dos pacientes, tais como estágio e gravidade da doença podem estar relacionados à sensibilidade/especificidade de um teste e a prevalência, porque diferentes tipos de pacientes são encontrados em situações de prevalência alta e baixa ${ }^{4 "}$. Isso também ocorre com o tracoma, pois se a prevalência é baixa tendo grande quantidade de casos leves, a sensibilidade do teste de IFD pode alterar-se.

As prevalências do tracoma inflamatório (TF/TI) no Estado de São Paulo ${ }^{6,8}$ são menores quando comparadas com as encontradas no Nordeste brasilei$\mathrm{ro}^{5,12,13,14} \mathrm{e}$ em áreas endêmicas de outros países subdesenvolvidos ${ }^{1,18,20}$. Deste modo, se as lâminas coletadas foram em sua maioria de casos clínicos leves e moderados, poderia ter ocorrido alteração na sensibilidade do teste.

O teste de IFD, apesar de ser o melhor teste laboratorial para ser utilizado em trabalho de campo, não apresenta sensibilidade suficiente para confirmar todos os casos clínicos diagnosticados de tracoma, não só pelas características do teste, mas também devido às características da doença, pois nem todos os casos podem ser confirmados laboratorialmente pelos testes atualmente disponíveis.

Segundo Fletcher e col. ${ }^{4}, 1989$ "é desejável dispor-se de um teste que seja altamente sensível e altamente específico. Infelizmente, com freqüência, isto não é possível". Entretanto, o teste de IFD pode ser usado para a confirmação da circulação do agente etiológico em uma população onde existe grande número de casos clínicos da doença.

De acordo com Taylor ${ }^{19}$ (1989) "o diagnóstico laboratorial da infecção clamidiana em geral e do tracoma em particular tem sido frustrado pela ocorrência frequiente de testes falsos-negativos. Isto é verdadeiro para as áreas endêmicas de tracoma, onde o exame clínico é fácil e o diagnóstico clínico da doença ativa é preciso".

Por todas as considerações feitas, conclui-se que em zonas endêmicas o diagnóstico clínico de tracoma continua sendo o critério para confirmação de casos, sempre e quando existir pessoal treinado e com conduta padronizada para a realização do diagnóstico clínico.

Recomenda-se a retirada de lâminas inadequadas para análise, quando da realização de estudos epidemiológicos envolvendo controles sadios, pois a inclusão delas aumentaria a quantidade de falsos-negativos, podendo alterar a sensibilidade, como também a especificidade, pela não detecção de falsospositivos.

\section{AGRADECIMENTO}

À Silvia Colombo, bióloga do Instituto Adolfo Lutz, pela participação na análise dos exames de imunofluorescência direta. 


\section{REFERÊNCIAS BIBLIOGRÁFICAS}

1. DAWSON, C.R. et al. Severe endemic trachoma in Tunísia II. A controlled therapy trial of topical chlortetracycline and erythromycin. Arch. Ophthalmol., 92:198-203, 1974.

2. DAWSON, C. R. et al. Guia prática de lucha contra el tracoma. Genebra, OMS, 1981.

3. ELBAGIR, A. \& MARDH, P.A. Evaluation of chlamydial tests in early trachoma. A.P.M.I.S., 98:276-80, 1990

4. FLETCHER, R.H. et al. Epidemiologia clínica, $2^{2}$ ed. Artes Médicas, Porto Alegre, 1989.

5. FREITAS, C.A. Prevalência do tracoma no Brasil. Rev. Bras. Malariol. Doenças. Trop., 28:227-380, 1976.

6. GENTIL,R.M. et al. Prevalence of trachoma in children of Franco da Rocha and Francisco Morato - São Paulo - Brasil - 1989. Invest. Ophthalmol. Vis Sci., 32: 737, 1991.

7. HAWKINS, D.A. et al. Rapid detection of Chlamydia trachomatis with monoclonal antibodies. Lancet, 2:38, 1984.

8. LUNA, E.J.A. et al. Epidemiology of trachoma in Bebedouro, State of São Paulo. Brazil: prevalence and risk factors. Int. J. Epidemiol., 21: 169 - 77, 1992.

9. ORGANIZACION MUNDIAL DE LA SALUD. Guia para el diagnóstico de laboratório del tracoma, Washington, D.C, 1981.( OPS - Publicacion científica $\mathrm{n}^{\circ} 408$ ).

10. QUINN, T.C. et al. Screening for Chlamydia trachomatis infection in an inner city population: a comparison of diagnostic methods. J. Infect Dis., 152 : 419-23, 1985.

11. RAPOZA, P.A. et al. Assessment of neonatal conjunctivitis with a direct imunofluorescent monoclonal antibody stain for Chlamydia, JAMA, 255 : 3369-73, 1986.
12. SCARPI, M.J. et al. Prevalência do tracoma no povoado de Mocambo, Estado do Ceará, Brasil. Arq. Bras. Oftal., 52, (5), 1989.

13. SCARPI, M.J. Aspectos do tracoma em três provoados do Estado da Bahia, São Paulo, 1989 [Tese de Doutorado Escola Paulista de Medicina].

14. SCARPI, M.J. et al. Prevalência de tracoma em bairro do Município de Palmares, Estado de Pernambuco, Brasil. Arq. Bras. Oftal., 53: 171-4, 1990.

15. SECRETARIA DE ESTADO DA SAÚDE DE SÃO PAULO. Manual de vigilância epidemiológica - tracoma: normas e instruções. São Paulo, 1991.

16. STEPHENS, et al. Monoclonal antibodies to Chlamydia trachomatis: antibody especificities and antigen characterization. J. Immunol., 128:1083-9, 1982.

17. TAM, R.R. et al. Culture independent diagnosis of chlamydia trachomatis using monoclonal antibodies. $N$. Eng. J. Med., 310:1146-50, 1984.

18. TAYLOR, H.R. et al. Detection of experimental Chlamydia trachomatis eye infection in conjuntival smears and in tissue culture by use of fluorescein conjugated monoclonal antibody. J. Clin. Microbiol., 20:391-5, 1984.

19. TAYLOR, H.R. et al. The epidemiology of infection in trachoma. Invest. Ophthalmol. Vis. Sci., 30:1823-33, 1989.

20. TAYLOR, H.R. et al. Longitudinal study of the microbiology of endemic trachoma, J. Clin. Microbiol., 29:1593-5, 1991.

21. THYLEFORS, B. et al. A simple system for the assessment of trachoma and its complications. Bull. World Health Organ., 65: 477-83, 1987. 